\title{
First Emergency Hemodialysis Session at the Nephrology Department of the Teaching Hospital of Yopougon: About 146 Cases
}

\section{Konan Serge Didier ${ }^{*}$, Kissou Pegdebamba François ${ }^{2}$, Guei Monlet Cyr ${ }^{2}$, Diopoh Sery Patrick ${ }^{1}$, Aka Jean Astrid1, Yao Kouamé Hubert' ${ }^{1}$}

\author{
${ }^{1}$ Nephrology-Internal Medicine Department D, CHU Treichville, Abidjan, Ivory Coast \\ ${ }^{2}$ Department of Nephrology, CHU Yopougon, Abidjan, Ivory Coast \\ Email: *sergedidier.konan@gmail.com, monletcyr@gmail.com, serydiopoh@gmail.com, \\ kissoupf@gmail.com, akaastrid3@yahoo.fr, yaohubert@yahoo.fr
}

\begin{abstract}
How to cite this paper: Didier, K.S., François, K.P., Cyr, G.M., Patrick, D.S., Astrid, A.J. and Hubert, Y.K. (2020) First Emergency Hemodialysis Session at the Nephrology Department of the Teaching Hospital of Yopougon: About 146 Cases. Open Journal of Nephrology, 10, 338-347. https://doi.org/10.4236/ojneph.2020.104033
\end{abstract}

Received: October 14, 2020

Accepted: November 20, 2020

Published: November 23, 2020

Copyright $\odot 2020$ by author(s) and Scientific Research Publishing Inc. This work is licensed under the Creative Commons Attribution International License (CC BY 4.0).

http://creativecommons.org/licenses/by/4.0/

\begin{abstract}
Context: Due to the late referral of the pads to the nephrologist and the lack of medical follow-up, many patients are admitted with complications from kidney disease requiring the urgent start of hemodialysis sessions. Purpose: Study the profile of emergency hemodialysis patients in order to ease their management. Methods: This was a retrospective, descriptive and analytical study carried out at the Nephrology Department of the Teaching Hospital of Yopougon from January 1st to December 31st, 2016. This study included all patients who had received a first session of hemodialysis in an emergency context. Results: We collected 146 patients with an average age of $39.80 \pm$ 14.55 years and a sex ratio of 0.6 for men. Before admission, patients were known as hypertensives (63.9\%), followed by CKD (23.9\%) and HIV-infected (8.2\%). The main clinical signs were hypertension (64.3\%), edema (44.5\%) and coma (30.1\%). Anemia was observed in $97.2 \%$ of cases and it was less than $8 \mathrm{~g} / \mathrm{dl}$ in $57.5 \%$. Kidney failure was chronic in $75.3 \%$ and acute in $24.6 \%$. Chronic nephropathies were glomerular (54.1\%), vascular (20.5\%). The main indications for hemodialysis were encephalopathy (33.5\%), severe uremia (28\%), acute pulmonary edema (19.8\%), persistent anuria (11.6\%) and hyperkalemia (5.4\%). The vascular approach was a catheter in $97.2 \%$ (femoral site in $53.4 \%$ and jugular in $43.8 \%$ and arteriovenous fistula in $2.7 \%$ ). Death was observed in $17.8 \%$. In univariate analysis, age $>65$ years $(p=0.04)$, coma $(p=0.004)$ and acute kidney failure $(p=0.02)$ were associated with the risk of death, and in multivariate analysis, only coma $(\mathrm{p}=0.024, \mathrm{OR}=5.88)$ seemed to be associated with mortality risk for our patients. Conclusion: Hemodialysis in an emergency situation is a common practice in the Teaching Hospital of Yopougon and mainly concerns patients with CKD.
\end{abstract}




\section{Keywords}

Kidney Failure, Hemodialysis, Emergency

\section{Introduction}

Kidney pathology constitutes a major public health problem in the world due to its frequency, high mortality rate and the costs of its treatment [1] [2].

Nephrological emergencies are not so frequent but they most often deal with management problems [3]. Their treatment often calls for hemodialysis, which can supplement the functions of cleaning uremic toxins and fluid and electrolytes balance, thereby improving their prognosis [4]. Despite these therapeutic advances made over the past 50 years, the mortality of patients with kidney impairment requiring emergency dialysis remains high [5] [6].

In 2010, replacement therapy ensured the survival of nearly 3 million patients worldwide, $78 \%$ of whom were on dialysis [7]. The incidence of acute kidney injury requiring hemodialysis is increasing and associated with high mortality [8].

In France, the 2011 REIN report estimated the incidence of dialysis patients at 144/million inhabitants [9]. In the United States of America, the rate of acute renal damage requiring extrarenal purification increased from 3227/million peope/year in 1996 to 5224/million people/year in 2003. In Canada, it increased from $0.8 \%$ to $3 \%$ from 1996 to 2010 [6].

In Senegal in 2016, a hospital study noted that $84.7 \%$ of patients in a hemodialysis center had received emergency sessions and that $34.2 \%$ of these patients had acute renal failure [10].

Data on emergency dialysis patients are scarce in our practice setting. Our work aims to study the profile of patients who have benefited from a first emergency hemodialysis session in order to facilitate decision-making for their management.

\section{Methods}

\subsection{Type and Scope of the Study}

Our study took place in the Nephrology department of the Teaching Hospital of Yopougon in Abidjan, Ivory Coast. This was a retrospective, descriptive and analytical study that took place over a period going from January 1st to December 31st, 2016.

This department includes an inpatient unit with a capacity of 20 beds, an outpatient unit, a hemodialysis unit with 07 generators, one of which is broken.

\subsection{Study Population}

We included all patients who received a first dialysis session in an emergency setting during the study period. Dialysis patients admitted urgently but who 
were not having their first dialysis session at that moment and those whose medical records were incomplete for the parameters sought were not included.

\subsection{Variables}

For each patient included, the following data were collected using a standardized survey sheet:

- Sociodemographic data: age, sex, profession, level of education;

- Co-morbidities: hypertension, diabetes, HIV, CKD, drug abuse (alcohol, tobacco, NSAIDs, PCI, use of traditional products);

- Clinical data: the department of origin, reasons for hospitalization, state of consciousness, state of hydration, blood pressure; edema, acute lung edema, urine output;

- Blood biological data: hemoglobin level, number of white blood cells and platelets, creatinine, urea, sodium, potassium, calcium, CRP;

- The type of renal failure: acute kidney injury (AKI) or chronic kidney desease (CKD) with the different mechanisms;

- Therapeutic data: hemodialysis with the indication of the session, the vascular access and the number of sessions, other treatments;

- Evolutionary data: duration of hospitalization, recovery or not of renal function, death.

\subsection{Definition of Operational Terms}

Renal function was assessed using the MDRD formula. Renal failure was defined by a glomerular filtration rate (GFR) of less than $60 \mathrm{ml} / \mathrm{min}$ for $1.73 \mathrm{~m}^{2}$. The chronic nature was defined by the length of renal failure (more than 3 months) and/or normochromium are generative normocytic anemia and/or hypocalcemia and/or associated renal atrophy. The IRC was said to be terminal (or stage 5) when it was less than $15 \mathrm{ml} / \mathrm{min}$.

In the absence of renal biopsies, the etiological research of renal failure was based on a set of clinical and paraclinical arguments. Thus, chronic glomerular nephropathy (CGN) has been evoked by the presence of proteinuria greater than $2 \mathrm{~g} / \mathrm{d}$ or proteinuria associated with hematuria. Chronic vascular nephropathy nephroangiosclerosis type was retained due to the existence of hypertension, low flow proteinuria $(<1 \mathrm{~g} / \mathrm{d})$, and renal failure associated with signs of hypertensive retinopathy in the fundus. Nephropathy associated with HIV has been evoked in the presence of massive proteinuria without arterial hypertension or hematuria, in any patient infected with HIV and of recent discovery ( $<3$ months), diabetic nephropathy in the presence of proteinuria greater than $500 \mathrm{mg} / 24$ hours associated with diabetic retinopathy on fundus examination, chronic tubulointerstitial nephropathy (CTIN) before the existence of proteinuria $(<1 \mathrm{~g} / 24 \mathrm{~h})$ associated with leukocyturia without germ and kidneys with irregular and dented outlines.

Functional acute kidney failure (AKI) was retained in the presence of renal 
hypoperfusion factor (diarrhea, vomiting, low cardiac output) or in front of signs of extracellular dehydration. Obstructive AKI was retained in the presence of bilateral dilation of the pyelocalicular cavities. Organic AKI was retained after exclusion of functional and obstructive AKIs.

Arterial hypertension was defined by the observation of blood pressure levels greater than or equal to $140 \mathrm{mmHg}$ systolic-wise and/or greater than or equal to $90 \mathrm{mmHg}$ diastolic-wise. The arterial pressure was divided into three grades: grade 1 or mild hypertension between 140 and $159 \mathrm{mmHg}$ systolic-wise and between 90 and $99 \mathrm{mmHg}$ diastolic-wise; grade 2 or mean hypertension between 160 and $179 \mathrm{mmHg}$ systolic-wise and between 100 and $109 \mathrm{mmHg}$ diastolic-wise; grade 3 or severe hypertension for blood pressure greater than or equal to $180 \mathrm{mmHg}$ systolic-wise and greater than or equal to $110 \mathrm{mmHg}$ diastolic-wise.

Anemia was defined as a hemoglobin level less than $12 \mathrm{~g} / \mathrm{dl}$. It was said to be severe when the hemoglobin level was less than $8 \mathrm{~g} / \mathrm{dl}$ and moderate between 8 and $12 \mathrm{~g} / \mathrm{dl}$.

\subsection{Statistical Analysis}

The data were entered using Excel software and analyzed using SPSS software in version 22. The statistical test used was the exact chi-square test with a significance level $\mathrm{p}<0.05$.

\section{Results}

During the study period, 213 patients received emergency dialysis in the ward. Of these, 146 met the inclusion criteria. The patients' medium age was $39.80 \pm$ 14.55 years with the extremes of 13 and 85 years. The age group of [35 - 65] years was the most represented with $54.7 \%$. We observed $59.5 \%$ of male subjects and $40.4 \%$ of female subjects.

Patients' medical history was dominated by hypertension (63.9\%), CKD (23.9\%) and HIV-infection (8.2\%). The main clinical signs were hypertensive surge (64.3\%), edema (44.5\%) and coma (30.1\%) (Table 1). This hypertension was grade 3 in $42.5 \%$ of cases.

Anemia was observed in $97.2 \%$ of cases and it was less than $8 \mathrm{~g} / \mathrm{dl}$ in $57.5 \%$. The other laboratory abnormalities were hyperkalemia (28\%), hypocalcemia (70.1\%), hyponatremia (68.7\%) and elevated C Reactive Protein (CRP) (93.3\%) (Table 1).

Kidney failure was chronic in $75.3 \%$ and acute in $24.6 \%$. Chronic nephropathies were glomerular (54.1\%), vascular (20.5\%).

The main indications for hemodialysis were encephalopathy (33.5\%), severe uremia (28\%), acute lung edema (19.8\%), persistent anuria (11.6\%) and hyperkalaemia (5.4\%).

The vascular access was a catheter in $97.2 \%$ (femoral site in $53.4 \%$ and jugular in $43.8 \%$ ) and an arteriovenous fistula in $2.7 \%$. 
Table 1. General characteristics of the patients.

\begin{tabular}{|c|c|c|c|c|c|}
\hline Variables & $\begin{array}{c}\text { Total } \\
(n=146)\end{array}$ & $\begin{array}{c}\text { Deceased } \\
(n=26)\end{array}$ & $\begin{array}{c}\text { alive } \\
(n=120)\end{array}$ & $p$ & OR $(\mathrm{IC}=95 \%)$ \\
\hline \multicolumn{6}{|l|}{ Sex } \\
\hline Male & $59.6 \%(87 / 146)$ & $61.5 \%(16 / 26)$ & $59.1 \%(71 / 120)$ & 0.8 & \\
\hline Female & $40.4 \%(59 / 146)$ & $38.6 \%(10 / 26)$ & $40.8 \%(49 / 120)$ & 0.8 & \\
\hline \multicolumn{6}{|l|}{ Age (years) } \\
\hline$<35$ & $39.7 \%(58 / 146)$ & $23.0 \%(6 / 26)$ & $43.3 \%(52 / 120)$ & 0.05 & \\
\hline [35-65] & $54.7 \%(80 / 146)$ & $61.5 \%(16 / 26)$ & $53.3 \%(64 / 120)$ & 0.4 & \\
\hline$\geq 65$ & $5.4 \%(8 / 146)$ & $15.3 \%(4 / 26)$ & $3.3 \%(4 / 120)$ & 0.04 & $\begin{array}{c}4.18 \\
(1.04-16.8)\end{array}$ \\
\hline \multicolumn{6}{|l|}{ Comorbidities } \\
\hline Hypertension & $63.6 \%(93 / 146)$ & $53.8 \%(14 / 26)$ & $65.8 \%(79 / 120)$ & 0.24 & \\
\hline CKD & $23.9 \%(35 / 146)$ & $15.3 \%(4 / 26)$ & $25.8 \%(31 / 120)$ & 0.25 & \\
\hline HIV & $8.2 \%(12 / 146)$ & $38 \%(1 / 26)$ & $9.1 \%(11 / 120)$ & 0.3 & \\
\hline \multicolumn{6}{|l|}{ Clinical Signs } \\
\hline Hypertension & $64.3 \%(94 / 120)$ & $46.1 \%(12 / 26)$ & $68.3 \%(82 / 120)$ & 0.1 & \\
\hline Edema & $44.5 \%(65 / 146)$ & $42.3 \%(11 / 26)$ & $45 . \%(54 / 120)$ & 0.3 & \\
\hline Coma & $30.1 \%(44 / 146)$ & $57.6 \%(15 / 26)$ & $24.1 \%(29 / 120)$ & 0.008 & $\begin{array}{c}7.14 \\
(1.6-30.8)\end{array}$ \\
\hline Dehydration & $12.3 \%(18 / 146)$ & $23.1 \%(6 / 26)$ & $10 \%(12 / 120)$ & 0.06 & \\
\hline Lung edema & $6.8 \%(10 / 146)$ & $3.8 \%(1 / 26)$ & $7.5 \%(9 / 120)$ & 0.8 & \\
\hline \multicolumn{6}{|l|}{$\begin{array}{l}\text { Blood pressure } \\
\text { grade }\end{array}$} \\
\hline 1 & $14.9 \%(14 / 94)$ & $19.2 \%(5 / 26)$ & $13.2 \%(9 / 68)$ & 0.06 & \\
\hline 2 & $42.5 \%(40 / 94)$ & $11.5 \%(3 / 26)$ & $54.4 \%(37 / 68)$ & 0.05 & $\begin{array}{c}0.29 \\
(0.08-1.03)\end{array}$ \\
\hline 3 & $42.5 \%(40 / 94)$ & $15.3 \%(4 / 26)$ & $52.9 \%(36 / 68)$ & 0.13 & \\
\hline \multicolumn{6}{|l|}{ Biology } \\
\hline Elevated CRP & $93.3 \%(127 / 136)$ & $92.3 \%(24 / 26)$ & $85.8 \%(103 / 120)$ & 0.7 & \\
\hline Hypocalcemia & $70.1 \%(54 / 146)$ & $26.9 \%(7 / 26)$ & $39.1 \%(47 / 120)$ & 0.6 & \\
\hline Hyponatremia & $68.7(99 / 144)$ & $65.3 \%(17 / 26)$ & $39.1 \%(47 / 120)$ & 0.51 & \\
\hline $\mathrm{Hb}<8$ & $57.5 \%(84 / 146)$ & $50 \%(13 / 26)$ & $59.1 \%(71 / 120)$ & 0.61 & \\
\hline Hyperkaliemia & $28.1 \%(41 / 146)$ & $42.3 \%(11 / 26)$ & $25 \%(30 / 120)$ & 0.06 & \\
\hline $\begin{array}{l}\text { Acute Kidney } \\
\text { Injury }\end{array}$ & $24.6 \%(36 / 146)$ & $42.3 \%(11 / 26)$ & $20.8 \%(25 / 120)$ & 0.02 & $\begin{array}{c}2.7 \\
(1.1-6.8)\end{array}$ \\
\hline
\end{tabular}

The outcome was favorable in $82.2 \%$ and death observed in $17.8 \%$. Kidney function stabilized in $71.9 \%$ and normalized in $10.2 \%$. In univariate analysis, age $>65$ years $(\mathrm{p}=0.04)$, coma $(\mathrm{p}=0.004)$ and acute acute kidney injury $(\mathrm{p}=$ 0.02 ) were associated with the risk of death (Table 1).

In multivariate analysis, only coma seemed to be associated with the risk of mortality in our patients (Table 2). 
Table 2. Risk factor for death after multivariate logistic regression analysis.

\begin{tabular}{cccc}
\hline Variables & $P$ & OR & IC (95\%) \\
\hline Age $>$ 65 ans & 0.2 & 0.4 & $0.07-1.8$ \\
AKI & 0.2 & 0.5 & $0.18-13$ \\
Coma & 0.02 & 5.8 & $1.2-33.3$ \\
\hline
\end{tabular}

\section{Discussion}

This work describes the profile of patients undergoing their first hemodialysis session in an emergency situation. The majority of these were young adults. Our results are similar to those found by Yaya Kane et al. in Senegal [10] who noted an average age of 41.3 years. On the other hand, our patients seemed younger than those of Dali Youcef et al. in Algeria [11] who had found a medium age of $57.8 \pm 16$ years. This difference could be explained by the difference in life expectancy which seems to be higher in Maghreb.

The male predominance observed in our work is found in all the African series [11] [12]. This could be explained by the predominance of Kidney disease in men.

The comorbidities were dominated by hypertension found in one out of ten patients, followed by HIV infection. Fayrouz Zemed et al observed hypertension in 46\% of cases in Morocco in 2017 [13]. In our context, hypertension followed by HIV infection is the two main risk factors for chronic renal failure [14].

Almost one in four patients (24\%) had a known CKD. The fact that the latter begin their hemodialysis sessions under emergency conditions could be explained by the high cost of treatment and/or the availability of centers. This would be added the refusal to accept the disease in some cases.

The clinical signs vary according to the departments in which the studies are carried out. Thus, the hypertensive surge observed in six out of ten patients in our study is a common situation in nephrology. In intensive care settings, neurological disorders are frequent and may affect eight out of ten patients as observed by Fayrouz Zemed et al. [12].

CKD was predominant and found in over two-thirds of our patients. In Algeria, Dali Youcef [11] noted a predominance of AKIs with 65\%. This difference could be explained by the difficulty of access to hemodialysis by patients in our context. This difficulty could be attributable not only to the high cost of dialysis in private centers but also to the availability of public centers, which remains limited.

The probable etiologies of CKD were dominated by CGN with $70.91 \%$ of cases. Our results corroborate with those of the numerous studies that show a high proportion of CGN in the aetiologies of especially in our context [14].

In our study, the indications for hemodialysis were dominated by uremic encephalopathy and severe uremia. Other authors [11] [15] have reported hyperkalemia and anuria as the main indications for emergency dialysis. This difference could be explained by the predominance of CKD cases in our study 
versus a predominance of AKIs in these studies.

The catheter is the main vascular access for emergency hemodialysis, as reported by various authors [11] [12] [13] [15]. The installation site varies according to the habits of the services. Thus, the femoral catheter was the most used followed by the jugular catheter in our patients. Dali Youcef et al. [11] reported the femoral catheter in $72.5 \%$, the site in $15 \%$ and the AVF in $12.5 \%$.

The mortality of $17.80 \%$ in our series was lower than that observed in the Moroccan series, respectively 32.2\% [13] and 70\% [15].

The high proportion of CKD cases in our work and the comorbidities of the patients could explain this difference. When analyzing the cases of AKI in our patients, mortality was in the order of $30.55 \%$. In the sub-Saharan African series, mortality varies between $34.1 \%$ [16] and $42.1 \%$ [10] in the event of AKI. Globally, AKI-related mortality can reach $50 \%$ according to some meta-analyzes and this mortality could be higher in the absence of hemodialysis [6] [17].

On univariate analysis, age > 65 years, coma, and AKI appeared to be risk factors for mortality. But in multivariate analysis, only coma was significantly linked to death. Talbi Sofia et al. [13] reported that hyperkalaemia was significantly associated with death in emergency hemodialysis AKIs. In the study by Suter Mendonça et al. [18], age $\geq 65$ years was a risk factor for death in AKI.

\section{Conclusions}

Hemodialysis in an emergency is a common practice at the Yopougon University Hospital. Our patients were predominantly young with a predominance of men. Almost all of the patients were hospitalized for various reasons dominated by neurological disorders and edema. The main physical signs were hypertension, edema and coma. Apart from very high urea levels and serum creatinine, anemia and inflammatory syndrome were found in almost all of our patients.

CKD cases were predominant and found in three out of four patients with CGN as the main initial nephropathy. Uremic encephalopathy dominated the indications for the hemodialysis session. The femoral catheter was the most widely used vascular access.

Mortality was $17.80 \%$ and higher in AKI cases. Coma seems to be a factor of poor prognosis.

It turns out that emergency hemodialysis is a critical situation especially for AKI cases. It is therefore imperative to be prompt in performing hemodialysis.

\section{Limitations of the Study}

Our study had limitations due to its retrospective nature. The information sought in the clinical records of patients was sometimes not complete.

\section{Conflicts of Interest}

The authors declare no conflicts of interest regarding the publication of this paper. 


\section{References}

[1] Bello, A.K., Levin, A., Tonelli, M., Okpechi, I.G., Feehally, J., Harris, D., et al. (2017) Assessment of Global Kidney Health Care Status. JAMA, 317, 1864-1881. https://doi.org/10.1001/jama.2017.4046

[2] Fouda, H., Ashuntantang, G., Kaze, F. and Halle, M.-P. (2017) Survival among Chronic Hemodialysed Patient in Cameroon. Pan African Medical Journal, 26, 97.

[3] Suisse, D. (2016) Quand appeler le néphrologue aux urgences. Revue Médicale Suisse, 12, 398-403.

[4] James, M.T., Heerspink, H.J.L., Pollock, C.A. and Stevens, P.E. (2018) Improving the Prognosis of Patients with Severely Decreased Glomerular Filtration Rate (CKD G4+): Conclusions from a Kidney Disease Improving Global Outcomes (KDIGO) Controversies Conference. Kidney International, 93, 1281-1292.

[5] Thervet, E. (2017) Traité de Néphrologie. Editions Lavoisier Médecine Sciences.

[6] Town, C., Mehta, R.L., Cerdá, J., Burdmann, E.A., Tonelli, M., García-garcía, G., et al. (2015) Congress International Society of Nephrology's 0by25 Initiative for Acute Kidney Injury (Zero Preventable Deaths by 2025): A Human Rights Case for Nephrology. The Lancet, 385, 2616-2643. https://doi.org/10.1016/S0140-6736(15)60126-X

[7] Liyanage, T., Ninomiya, T., Jha, V., Neal, B., Patrice, H.M., Okpechi, I., et al. (2013) Worldwide Access to Treatment for End-Stage Kidney Disease. The Lancet, 385, 1975-1982. https://doi.org/10.1016/S0140-6736(14)61601-9

[8] Kolhe, N.V., Muirhead, A.W., Wilkes, S.R., Fluck, R.J. and Taal, M.W. (2015) National Trends in Acute Kidney Injury Requiring Dialysis in England between 1998 and 2013. Kidney International, 88, 1161-1169.

https://doi.org/10.1038/ki.2015.234

[9] Couchoud, C., Lassalle, M. and Jacquelinet, C. (2013) Rapport Rein 2011-Synthèse. Néphrologie Thérapeutique, 9, S3-S6. https://doi.org/10.1016/S1769-7255(13)70036-1

[10] Yaya, K., De, S., Aristide, H., Dantec, L. and Sénégal, D. (2016) Décentralisation De La Dialyse Au Sénégal: Expérience d'un an du centre de Tambacounda à l'Est du Pays. European Scientific Journal, 12, 164-173. https://doi.org/10.19044/esj.2016.v12n36p164

[11] Dali Youcef, H.S. (2016) La Dialyse en Urgence. Thèse Médecine 2017. Université Abou Bekr Belkaid Tlmen, Algerie.

[12] Farouz, Z. (2017) Epuration extrarénale en réanimation. Thèse de médecine, Université Cadi Ayyad Marrakech (Maroc).

[13] Talbi, S. (2011) Hémodialyse en situation d'urgence (à propos de 207 cas). Thèse de Médecine, Université Sidi Mohammed Ben Abdellah Fès (Maro).

[14] Yao, H.K., Konan, S.D., Sanogo, S., Diopoh, S.P. and Diallo, A.D. (2018) Prevalence and Risk Factors of Chronic Kidney Disease in Cote D'Ivoire: An Analytic Study Conducted in the Department of Internal Medicine. Saudi Journal of Kidney Diseases and Transplantation, 29, 153-159. https://doi.org/10.4103/1319-2442.225201

[15] Bouda, R. (2016) Epuration extrarénale en réanimation (à propos de 40 cas). Thèse de médecine, Université Cadi Ayyad Marrakech (Maroc).

[16] Adu, D., Okyere, P., Doima, V., Malekole, M. and Osafo, C. (2016) Community-Acquired Acute Kidney Injury in Adults in Africa. Clinical Nephrology, 86, S48-S52. https://doi.org/10.5414/CNP86S121 
[17] Igiraneza, G., Ndayishimiye, B., Nkeshimana, M., Dusabejambo, V. and Ogbuagu, O. (2018) Clinical Profile and Outcome of Patients with Acute Kidney Injury Requiring Hemodialysis: Two Years' Experience at a Tertiary Hospital in Rwanda. BioMed Research International, 2018, Article ID: 1716420.

https://doi.org/10.1155/2018/1716420

[18] Suter, P.M., Moreno, R., Dearden, N.M., Antonelli, M., Takala, J., St, A., et al. (2000) Acute Renal Failure in the ICU: Risk Factors and Outcome Evaluated by the SOFA Score. Intensive Care Medicine, 26, 915-921.

https://doi.org/10.1007/s001340051281 


\section{Appendix}

\section{Standardized Survey Sheet}

Hospitalization file number:

1) DEMOGRAPHIC DATA

Age: .... Years Sex: $\mathrm{M} \square \mathrm{F} \square$

Level of study: primary $\square$ secondary $\square$ University $\square$ lliterate $\square$

Profession:

2) CLINICS

Reason for admission

Antecedents

Hypertension: Yes $\square$ No $\square$

Diabetes: Yes $\square$ No $\square$; CKD: Yes $\square$ No $\square$; HIV: Yes $\square$ No $\square$

Taking toxic substances: Tobacco: Yes $\square$ No $\square$; alcohol: Yes $\square$ No $\square$;

Traditional medicines: Yes $\square$ No $\square$; NSAIDs: Yes $\square$ No $\square$,

Exams

State of consciousness: State of hydration:

Blood pressure: $\mathrm{mmHg}$

3) BLOOD BIOLOGY

WBC ....../ $/ \mathrm{mm}^{3}$, Hb: ..... g/dL, Platelets: ... $\times 10^{3} / \mathrm{mm}^{3}$, Urea ....... g/L Creatinine .....mg/L, CRP: .....mg/L, $\mathrm{Na}^{+}:$......MEq/L, $\mathrm{Ca}^{+}:$....mg/L, $\mathrm{K}^{+}:$.....mEq/L

4) DIAGNOSTIC

Acute Kidney Injury: Yes $\square$ No $\square$ if yes type:

Chronic Kidney Desease: Yes $\square$ No $\square$ if yes type:

5) TREATMENT

Hemodialysis

HD indication:

Vascular access:

Number of sessions:

Other treatments

Blood Transfusion: Yes $\square$ No $\square$

Antibiotic therapy: Yes $\square$ No $\square$

6) EVOLUTION

Healing: Yes $\square$ No $\square$

Stabilization: Yes $\square$ No $\square$

Death: Yes $\square$ No $\square$ if Yes cause:

Duration of hospitalization: 